\title{
Whole-cell cancer vaccination: from autologous to allogeneic tumor- and dendritic cell-based vaccines
}

\author{
Tanja D. de Gruijl • Alfons J. M. van den Eertwegh • \\ Herbert M. Pinedo $\cdot$ Rik J. Scheper
}

Received: 28 February 2008 / Accepted: 12 May 2008 / Published online: 4 June 2008

(C) The Author(s) 2008

\begin{abstract}
The field of tumor vaccination is currently undergoing a shift in focus, from individualized tailor-made vaccines to more generally applicable vaccine formulations. Although primarily predicated by financial and logistic considerations, stemming from a growing awareness that clinical development for wide-scale application can only be achieved through backing from major pharmaceutical companies, these new approaches are also supported by a growing knowledge of the intricacies and minutiae of antigen presentation and effector T-cell activation. Here, the development of whole-cell tumor and dendritic cell (DC)-based vaccines from an individualized autologous set-up to a more widely applicable allogeneic approach will be discussed as reflected by translational studies carried out over the past two decades at our laboratories and clinics in the vrije universiteit medical center (VUmc) in Amsterdam, The Netherlands.
\end{abstract}

Keywords Allogeneic · Autologous · Dendritic cell · Whole-cell tumor vaccine

\footnotetext{
This article is a symposium paper from the conference "The European Society for Medical Oncology (ESMO) and the European Society for Cancer Immunology and Immunotherapy (ESCII) International Symposium on Immunology", held in Athens, Greece, on 15-17 November 2007.
}

T. D. de Gruijl · A. J. M. van den Eertwegh · H. M. Pinedo Division of Immunotherapy, Department of Medical Oncology, Vrije Universiteit medical Center, Amsterdam, The Netherlands

\section{R. J. Scheper ( $\square)$}

Department of Pathology, Vrije Universiteit Medical Center, De Boelelaan 1117, 1081 HV Amsterdam, The Netherlands e-mail: rj.scheper@vumc.nl

\section{Autologous whole-cell tumor vaccination}

Autologous tumor cells are an obvious source of tumorassociated antigens (TAA) for vaccination purposes, since, by definition, all relevant candidate TAA should be contained within them. Vaccination with irradiated tumor cells has been studied in various animal models as early as the 1970s. Pioneered by Hanna et al. irradiated hepatocellular carcinoma cells were used as a vaccine in a guinea pig model and, admixed with bacillus calmette-guérin (BCG) as an immune adjuvant, were found to generate protective immunity against subsequent challenge with syngeneic non-irradiated tumor cells $[17,18]$. Of note, these early guinea pig studies revealed the importance of vaccinating with live tumor cells, suggesting either a) the direct involvement of the tumor cells themselves in antigen presentation or $b$ ) the importance of prolonged expression and release of TAA to allow for sufficient uptake by and activation of immune effector cells. Before general acceptance of the concept of cross-priming, the former was actually regarded as the more obvious explanation.

\section{Colorectal cancer}

Building on this pre-clinical work, Hoover et al. conducted a clinical trial in which patients with stage II/III colorectal cancer were vaccinated with irradiated autologous tumor cells and BCG, randomized versus surgery alone [24]. Subgroup analysis revealed significant overall and disease-free survival for vaccinated patients. In addition, delayed type hypersensitivity (DTH) reactions to autologous tumor cells suggested the presence of tumor-specific immunity. Side effects were minimal and consisted mostly of ulceration of the vaccination sites caused by the BCG adjuvant.These promising results prompted the initiation of a large phase 
III study of stage II/III colon cancer patients conducted under the auspices of the eastern cooperative oncology group (ECOG) [20]. This study differed from the Hoover study in that, due to the large number and wide geographic distribution of participating sites, each site manufactured its own vaccines. In an intent-to-treat analysis of all randomized patients, no significant differences were observed between the two treatment arms in time to recurrence or overall survival. In the ECOG study, $12 \%$ of all vaccines failed to meet quality control specifications (in terms of cell number and/or viability), and $15 \%$ of the vaccinated patients failed to develop DTH reactions to tumor cells alone. Importantly, DTH reactivity to autologous tumor cells did correlate with survival [20]. It was therefore assumed that poor quality of a part of the vaccines and variability introduced by manufacture at different sites were at the root of the disappointing clinical results of this study. Indeed, survival analysis of patients who were treated with vaccines that met standardization criteria and who actually developed anti-tumor immunity (as determined by DTH reactivity) did show a significant improvement in overall survival. These findings underlined the necessity of standardized vaccine manufacture to make any meaningful comparisons in outcome between vaccinees: a particular challenge in an autologous set-up.

A third phase III study was conducted at our laboratory in the VUmc, involving 254 patients with stage II/III colon cancer [62]. This pivotal study differed from the previous ECOG study in that a centralized manufacturing laboratory (i.e.the VUmc) supported the 12 participating hospitals, resulting in $98 \%$ quality approved vaccines and a rate of $97 \%$ measurable DTH reactivity upon vaccination (i.e. $>5$ $\mathrm{mm})$. In an intent-to-treat analysis, autologous tumor cell + BCG vaccination significantly reduced the rate of disease recurrence by $44 \%$ in patients with stage II/III colon cancer, but the overall survival was not significantly affected. A larger impact was apparent in stage II disease, where a $61 \%$ risk reduction for recurrences and a trend toward improved overall survival was observed. These data clearly indicate that the centralized and routine manufacture of qualitycontrolled vaccines is of the utmost importance for the performance of a successful immunization trial.

A meta-analysis was performed which included the above described three randomized trials for colorectal cancer [19]. In the intent-to-treat meta-analysis of all 723 patients who received either a three- or a four-vaccine regimen, recurrence-free survival was significantly improved by autologous whole-cell tumor vaccination. However, no significant overall survival benefit could be demonstrated.

While these studies showed promise, more recent FDA prerequisites have complicated the production and quality assurance of these autologous whole-cell tumor based vaccines for colon cancer. Particularly sterility requirements are posing a considerable challenge for an autologous whole-cell vaccine derived from an organ as rife with commensal bacteria as the colon. These restrictions were enforced despite the fact that empirically, in over 200 vaccinated patients, these colon-associated bacteria (whether admixed with BCG or not) were never found to cause any untoward side effects. These regulatory hurdles, combined with financial restraints, have led to the premature termination of a Phase III trial carried out in our clinics at the VUmc, studying the effect of whole-cell colon tumor vaccination combined with 5-FU chemotherapy versus chemotherapy only, in patients with Stage III colon cancer.

\section{Melanoma}

Fostering the autologous whole-cell vaccine + BCG approach, a clinical study was performed at the VUmc with 81 stage III/IV metastatic melanoma patients [1]. Forty-nine of these patients had no sign of residual disease after metastasectomy, although the chances of tumor recurrence were considered high. After metastasectomy whole-cell tumor vaccines were produced of the resected tumor tissue. One month after surgery the first of three weekly administered irradiated vaccines was administered intradermally in one of the lower extremities. In patients with evidence of disease during the vaccination period $(n=38)$ no clinical responses occurred and no survival benefit was apparent when compared to historical controls. In patients without evidence of disease (stage III, $n=35$ and stage IV, $n=14$ ), the 5 -year overall survival rate approximated $45 \%$, which was superior to historical controls (at $35 \%$ and $20 \%$ for Stage III and IV, respectively) [1]. In addition, DTH reactivity to tumor cells was found to correspond positively with overall survival [1]. Finally, this study revealed that the size of DTH-reactions waned after consecutive non-BCG-containing vaccinations, even in patients that after a follow-up period of over five years proved to be free of melanoma. This observation strongly suggests that booster vaccinations can only be effective when co-administered with an immunostimulating adjuvant.

Berd et al. also developed and clinically tested an autologous melanoma cell vaccine, haptenated with dinitrophenyl (DNP), and also combined it with BCG as adjuvant [3]. After an inclusion period of more than 10 years they reported a 5-year relapse free survival of 33\% and an overall survival of $44 \%$ for a non-randomized trial with 214 enrolled stage III melanoma patients. These survival rates were considered superior to historical control survival data. Of note, they also observed an association of overall survival and disease free survival with the induction of DTH reactivity to unmodified (non-haptenated) autologous melanoma cells [3]. 


\section{Renal cell cancer}

In a large multi-center Phase III trial carried out in Germany, 558 patients with a renal cell tumor were pre-operatively randomized to receive either six monthly intradermal autologous tumor vaccines or no adjuvant therapy [30]. Tumor cells were pre-treated with IFN- $\gamma$ to upregulate MHC levels and underwent six freeze-thaw cycles prior to administration. No further immune adjuvants were added to the vaccines. 5-year progression-free survival was $77.4 \%$ in the vaccinated patients as compared to $67.8 \%$ in the untreated patients. Although promising, these results might have been improved upon through the inclusion of a strong immune adjuvant in the vaccine formulation. Although BCG proved its worth as immune adjuvant, the resulting ulcers at vaccination sites eventually disqualified it as the adjuvant of choice for cancer vaccination. The identification of hypomethylated $\mathrm{CpG}$ sequences derived from bacterial DNA as the immune-activating component of BCG $[31,32]$ led to the design of a Phase II trial at the VUmc in which patients with advanced Renal Cell Cancer were vaccinated with an autologous whole-tumor cell vaccine admixed with a combination of CpG (type-B, PF-3512676), IFN $\alpha$, and Granulocyte-Macrophage Colony-Stimulating Factor (GM-CSF) as adjuvant. The first three induction vaccinations were given weekly followed by subcutaneous administration of IFN- $\alpha$ (6 MIU) and PF-3512676 (8 mg biweekly). After 3 months tumor evaluation was performed and in case of a remission or stable disease patients continued with 3 monthly vaccinations and PF-3512676/IFN- $\alpha$. This vaccination schedule resulted in a $20 \%$ clinical response rate in association with a strong anti-tumor DTH skin reactivity [59]. This study clearly showed the equivalence of this adjuvant combination to BCG in terms of immune activation, without the ulcer formation usually associated with BCG.

\section{GVAX: from autologous towards allogeneic tumor vaccination}

GM-CSF is a $23-\mathrm{kDa}$ glycoprotein that was initially developed for its activity as a hematopoietic growth factor [52]. Subsequent studies revealed its interesting immunological features [8, 10]. GM-CSF can overcome tumor-induced immune suppression and promotes the recruitment and maturation of specialized antigen-presenting cells (APC). GM-CSF-mediated activation of APC results in upregulation of MHC class II, co-stimulatory molecules and cytokine production. It increases antibody responses and cellular immunity after immunization. These combined features have made GM-CSF the most commonly used cytokine to boost anti-tumor immunity $[8,10,29]$. In a murine melanoma model Dranoff et al. demonstrated the potency of prophylactic GM-CSF-transduced autologous tumor cell vaccines in prevention of tumor outgrowth [9]. Based on this preclinical work, autologous melanoma tumor cells, transduced with GM-CSF (GVAX), were applied clinically and shown to induce tumor-specific immunity and durable anti-tumor responses in a number of trials [22].

Mouse studies clearly demonstrated the efficacy of GVAX to depend on the cross-presentation of vaccinederived TAA to specific cytotoxic T lymphocytes (CTL) in vivo [22]. This process of cross-priming is facilitated by the activation of professional APC, the so-called Dendritic Cells (DC), by GM-CSF. This finding led to the realization that allogeneic cells would also present a viable source of TAA, which would be taken up by DC and then presented in the context of appropriate MHC alleles to autologous CTL. Advantages to the use of allogeneic cells are obvious: (1) through the use of antigenically well-defined cell lines one has access to a sustained and virtually limitless source of TAA, (2) the use of cell lines allows for the highly standardized and large-scale production of allogeneic vaccines, (3) the use of a single batch of allo-vaccines for all vacinees, independent of HLA haplotype, eliminates variability in the quality and composition of the vaccines and facilitates reliable comparative analysis of clinical outcome, and (4) eliminating the need for the continuous production of tailor-made individual vaccines simplifies the logistics and reduces the laboriousness of the vaccine production and delivery process and increases its cost-effectiveness.

Taking these considerations into account, autologous GVAX approaches have been replaced by allogeneic GVAX formulations. Jaffee et al. tested an allogeneic pancreatic cancer vaccine as an adjuvant therapy after pancreaticoduodenectomy in a phase I dose-escalating study and found no noteworthy toxicity, while some patients showed increased DTH-skin reactivity to autologous tumor cells, indicative of the generation of relevant anti-tumor immunity [28].

\section{Prostate cancer}

Michael et al. showed the feasibility of allogeneic prostate cancer vaccination: vaccines consisting of three prostate tumor cell lines were i.d. injected monthly over the course of a year in patients with hormone refractory prostate cancer [35]. The first two vaccines were admixed with BCG. Decreases in PSA velocity were observed in 11/26 patients with an overall median time to disease progression of 58 weeks as compared to 28 weeks in historical controls. Interestingly, while non-responders showed a mixed Th1/Th2 response upon restimulation with a vaccine lysate, responders showed a Th1 cytokine release profile.

Prostate GVAX consists of two prostate cancer cell lines, LNCaP and PC-3, each of which has been genetically modified 
to secrete GM-CSF. Following manufacture of the transduced cell lines, the cells are lethally irradiated to prevent further cell division upon vaccination. In phase I/II studies the vaccine was generally well tolerated and demonstrated anti-tumor activity $[11,44,46]$. The largest of these was a multi-center phase I/II trial in 55 patients with HRPC [46]. Thirty-four patients with metastases showed an overall median survival of 26 months, which compares favorably with median survival times observed in phase II taxane chemotherapy trials in similar patients with HRPC [37, 42, 46]. Induction of sero-immune reactivity against the prostate cancer cells was demonstrated by Western blot. A smaller phase I/II trial was carried out in hormone therapy-naive patients with a prostate-specific antigen (PSA) relapse following radical prostatectomy and absence of radiological metastases [44]. Treatments were administered weekly via intradermal injections of Prostate GVAX for 8 weeks. Twenty-one patients were enrolled and treated. Toxicities included local injection-site reactions, pruritus, and flu-like symptoms. At 20 weeks post first treatment, 16 of 21 (76\%) patients showed a statistically significant decrease in PSA velocity compared with pre-vaccination $(P<0.001)$ [44]. Clinical efficacy of Prostate GVAX is currently tested in metastatic prostate cancer patients in two phase III randomized studies (VITAL-1 and -2). In the first study GVAX is compared to Docetaxel plus prednisone and in the second study GVAX in combination with docetaxel is compared to docetaxel alone. The results are eagerly awaited.

While GVAX monotherapy has shown moderate clinical efficacy, this may be improved upon through interference with checkpoints at the T-cell level that under normal circumstances serve to reinforce tolerance but that in tumor-conditioned environments may suppress appropriate anti-tumor immune responses. The CTL Antigen-4 (CTLA-4) receptor represents such a crucial checkpoint [12]. It is expressed on activated T-cells and binds to CD86 and CD80 on DC with higher avidity than its competitor ligand CD28. In contrast to CD28, CTLA-4 relays inhibitory signals to the $\mathrm{T}$ cell and blocks activating signals originating from CD28-CD86/CD80 interactions. CTLA-4 blockade breaks through inhibitory feedback loops in tumor-specific T-cells and may thus lead to expansion of effector CTL with possibly a higher functional avidity [12]. In mouse tumor models, the combination of GM-CSF-secreting vaccines and CTLA-4-blocking antibodies has resulted in improved anti-tumor immunity and protection from tumor outgrowth. Both in the B16 melanoma model and in TRAMP, a transgenic murine model of spontaneously arising prostate cancer, the administration of either anti-CTLA$4 \mathrm{mAbs}$ or vaccination with GM-CSF transfected tumor cells had minimal to no effect on tumor rejection. In marked contrast, treatment with the combination of anti-CTLA-4 and GM-CSF-transduced tumor cells at the time of tumor inoculation significantly reduced tumor incidence [26, 60, 61]. This anti-tumor effect was shown to be CTL-mediated and $\mathrm{T}$ helper cell (Th) independent, and indicates that CTLA-4 blockade can lower the threshold of required activating signals such that Th-mediated activation of DC is no longer needed for the provision of a "license to kill" to CTL [61]. While Phase I/II clinical trials studying monotherapy with either Prostate GVAX or anti-CTLA-4, have shown feasibility of treatment with either modality without severe side-effects and with modest signs of possible clinical efficacy [11, 44, 46, 47], the aforementioned pre-clinical studies clearly demonstrated a potentially increased efficacy of anti-CTLA-4 as part of a combinatorial approach with Prostate GVAX. This led to the initiation of a Phase I clinical study in the VUmc, in which chemo-naive patients with metastatic hormone refractory prostate cancer (HRPC) receive the allogeneic prostate GVAX immunotherapy combined with infusions of ipilimumab/antiCTLA-4. This trial represents the first clinical application of the GVAX/anti-CTLA4 combination. In the dose escalation part of this trial, the combination of GVAX immunotherapy with high doses of ipilimumab (3 or $5 \mathrm{mg} / \mathrm{kg}$ ) has led to promising clinical results with some clear PSA responses [16]. The trial has now entered its expansion phase with an accrual of 16 patients to be treated at the MTD of ipilimumab, determined in the escalation phase to be $3 \mathrm{mg} / \mathrm{kg}$. To demonstrate immune effects of this treatment and possibly correlate these with clinical efficacy, we are extensively monitoring dendritic and T-cell functions. The results may aid in the rational design of clinical followup studies. Final analysis will be performed after concluding the expansion phase of this Phase I trial.

\section{DC-based tumor vaccination: the case for an allogeneic source of DC}

DC are uniquely able to initiate primary immune responses. Myeloid DC differentiate from CD34 ${ }^{+}$hematopoietic progenitor cells (HPC) and can develop into two recognized subsets, Langerhans Cells (LC, expressing the characteristic C-type Lectin Langerin and containing Birbeck Granules [BG]), which are mostly found in stratified epithelia, and Interstitial DC (IDC, expressing the C-type Lectin DCSIGN), which are mostly located in connective tissues. Because of their critical role in orchestrating the immune response, DC are now widely applied in vaccines for the treatment of cancer [4]. So far, the vast majority of clinical vaccination trials utilized Monocyte-derived DC (MoDC, i.e. IDC equivalents), while only few trials have made use of DC derived from CD34+ precursors (CD34-DC [4]). Nevertheless, it has been suggested that CD34-DC are more effective anti-tumor T-cell inducers than MoDC, both in vitro and 
in clinical DC vaccination studies [2, 14]. This favorable effect might be due to "contaminating" LC in the CD34-DC preparations [38]. DC may be pulsed with TAA-derived epitopes in various ways: through loading with proteins or peptides, through incubation with tumor lysates or apoptotic bodies, through fusion with tumor cells, through transfection with DNA or RNA, or through viral transduction. In various trials anti-tumor immunity as well as clinical efficacy of DCbased tumor vaccination have been reported, particularly for melanoma [33]. So far, wide-scale implementation has proven to be unattainable for any of the tested DC-based vaccines. A case in point was recently provided by sipuleucel-T (APC8015), which consists of a DC-like fraction enriched from autologous peripheral blood, pulsed with a prostate TAA/GM-CSF fusion protein. Despite a favorable survival benefit in a randomized Phase III trial of 225 patients with metastatic prostate cancer [45] and an initial positive verdict on safety and clinical efficacy from an FDA advisory committee, it was denied FDA approval, just falling short of becoming the first FDA-approved cell-based vaccine product [15]. The FDA decision letter called for additional proof of clinical efficacy from an ongoing randomized Phase III trial (a new interim analysis of which is expected mid-2008) and more detailed information on the manufacturing process $[15,63]$. Certainly, multiple hurdles are to be taken in the development of such autologous DC precursor-based immunotherapies as they are: (a) hard to standardize, resulting in highly variable results, complicating the evaluation of clinical trials, and often resulting in negative clinical trial outcomes, (b) laborious and time consuming, and therefore c) very expensive [33]. These drawbacks have thusfar precluded wide-scale application of autologous DC-based vaccines. In addition, although conflicting reports exist on this matter, there have been indications for an inferior T-cell-stimulatory phenotype of DC derived from advanced cancer patients [21, 36], which would also argue against the use of autologous DC.

An alternative approach which has recently been explored is the use of allogeneic DC as vaccine vehicles. A major advantage of the use of alloDC is the feasibility of preparing large clinical-grade batches that may be used for all patients, thus providing a more standardized DC vaccine in terms of phenotype and maturation status. As with allogeneic tumor cell-based vaccines, bypassing the need for individually prepared vaccines represents a considerable logistic advantage. Although seemingly counter-intuitive, from a theoretical point of view alloDC-based vaccines might even induce a stronger vaccine-specific immune response than autoDC [13]. Since an estimated $1-10 \%$ of the circulating $\mathrm{T}$ cell repertoire is directed against allo-antigens, alloDC may be expected to trigger a broadly reactive T-cell response with two possible advantages: (1) activation of tumor-reactive T-cells through fortuitous cross-reac- tivity and (perhaps more likely and more importantly:) (2) allo-antigens on the DC may provide T helper (Th) epitopes aiding in the optimal activation of Cytotoxic T Lymphocytes (CTL) against the tumor-related vaccine payload [13].

Several mouse studies have compared the use of alloDC versus syngeneic DC as fusion partners for syngeneic tumor cells, creating a DC-tumor hybrid vaccine, and consistently shown equal or even superior protection against tumor outgrowth with alloDC $[43,48,51,58]$. The anti-tumor responses were mostly shown to be CTL-mediated. Mechanistically, observed advantages of the use of alloDC hybrids seemed to be related to skewing towards a type-1 cytokine response as compared to the use of syngeneic DC [43, 48, 58].

Various clinical trials have been carried out to validate the use of alloDC-based tumor vaccination and results so far have been mixed [23, 27, 36, 50, 55-57]. In these studies patients with metastatic RCC, with melanoma, or with earlystage B-cell chronic lymphocytic leukemia were vaccinated with alloDC, either loaded with tumor lysates or apoptotic bodies, or fused to autologous or allogeneic tumor cells. All studies showed the tolerability and safety of this approach, with some partial clinical responses, accompanied by evidence of tumor-specific T-cell activation. On the whole, alloDC based vaccines appeared less effective than autologous DC used in previous trials. This might be due to a lack in HLA class I matching [55, 56]. Of note, most favorable results in murine models were obtained with "semi-allogeneic" DC, i.e. alloDC that were partially MHC-matched [58]. While allo-MHC class II molecules may provide beneficial Th activity, it is likely that for a CTL response to be induced, at least partial MHC class I matching is required. This was recently confirmed by a vaccination study in colorectal cancer patients, showing that tumor lysate-loaded DC with one haplotype miss-match induced stronger anti-tumor immune responses, accompanied by stabilized or reduced CEA serum levels, as compared to fully autologous DC [50]. Similarly, vaccination with autologous melanoma/alloDC hybrids, which per definition would present TAA peptides in the context of matched (in this case autologous) HLA class I molecules, resulted in clinical responses, long survival times, and high-frequency post-vaccination $\mathrm{T}$ cell responses against a broad range of melanoma epitopes [55, 57]. These studies clearly demonstrate the feasibility of generating TAA-specific T-cell responses in vivo on an allo-background: anti-tumor responses were quite clearly not drowned out by collateral allo-T-cell responses.

\section{The MUTZ-3 cell line: a sustainable source of alloDC for vaccination purposes}

While CD34-DC may be more powerful vaccine vehicles than the more commonly used MoDC, the use of in vitro 
generated CD34-DC is complicated by the lenghty and laborious methodologies involved, considerable functional and phenotypic variability between batches (both intra- and inter-individual) and the extremely low frequency of CD $34^{+}$DC precursor cells in peripheral blood. A human $\mathrm{CD} 34^{+}$DC line would be an attractive alternative, allowing the preparation of large quantities of standardized alloDC that would provide an off-the-shelf alternative for autologous DC-based tumor vaccination purposes. Over the past 8 years we have gathered evidence that the cytokine-dependent $\mathrm{CD} 34^{+}$human acute myeloid leukemia (AML) cell line MUTZ-3 represents such a sustainable supply of DC [34, 39-41]. By matching for the HLA-A2 and/or -A3 alleles (both present on MUTZ-3), $>50 \%$ of patients should be eligible for MUTZ-3-based vaccination regimens.

MUTZ-3 is a heterogeneous AML cell line consisting of CD34+ and CD14+ cell populations [25]. CD34 ${ }^{+}$MUTZ-3 cells behave as the immortalized equivalents of $\mathrm{CD} 34^{+} \mathrm{DC}$ precursor cells $[34,40]$. Upon stimulation with specific cytokine cocktails, CD34 ${ }^{+}$MUTZ-3 progenitors pass through a $\mathrm{CD} 14^{+}$state, lose their proliferative capacity, and acquire a phenotype consistent with either classic IDC or LC with respective characteristic and mutually exclusive expression of DC-SIGN or Langerin and Birbeck Granules [40]. MUTZ3-DC display the full range of functional MHCand CD1d-mediated antigen processing and presentation pathways and upon maturation (induced by cocktails comprising IL-6, PGE2, TNF- $\alpha$, IL-1 $\beta$, IFN- $\alpha$, or Poly:IC) upregulate co-stimulatory molecules, express $\mathrm{CD} 83$, and display an enhanced allogeneic T-cell priming ability in mixed leukocyte reactions (MLR) [34, 40]. By extensive functional characterization of MUTZ3-DC (differentiated to either IDC or LC), we aimed to elucidate their ability to induce a specific T-cell response and to serve as a clinical vehicle of tumor vaccines [39, 41]. The lymph node (LN) homing potential of MUTZ3-DC was confirmed in a trans-well assay in response to the LN-derived chemokines CCL19 and CCL21 and shown to be comparable to MoDC [41]. This is in line with their CCR7 expression and suggestive of their in vivo ability to reach the paracortical T-cell areas of $\mathrm{LN}$. We demonstrated that functional (i.e. tumor-recognizing) CTL clones could be generated against multiple tumor-associated epitopes (derived from MART-1, CEA, Her-2/neu, and PSA) by stimulating CD8 $\beta^{+}$CTL precursors with peptideloaded allogeneic, HLA-A2-matched MUTZ3-DC (both IDC and LC) [39, 41]. Importantly, a consistent induction capacity, as determined by MHC tetramer (Tm) binding, was found in multiple donors (i.e. across a range of alloMHC haplotypes) and at an efficiency comparable to autologous peptide-loaded MoDC. TAA-specific CTLs generated by MUTZ3-DC were of low-to-intermediate functional avidity. Retroviral transduction with IL-12p70 significantly improved CTL priming efficiency of both MUTZ-3-derived
IDC and LC and resulted in priming of MART-1 specific CTL with higher functional avidity, a more defined memory-effector phenotype, and a higher cytolytic potential for MART-1-expressing melanoma cells [41].

Planned clinical trials are expected to demonstrate the efficacy of allo-DC cell lines in the in vivo priming of specific effector T-cells in the face of an ongoing competition with simultaneously primed allogeneic T-cells. It will be of particular interest to establish the number of effective booster vaccinations that can be administered following the prime vaccination, before allogeneic responses become too restrictive and alternative vaccine formulations may have to be applied in alternating prime-boost approaches.

\section{The future: from whole-cell vaccines to DC-targeted vaccines?}

While currently explored allogeneic approaches in whole tumor cell and/or DC-based vaccination procedures represent an improvement in terms of standardization and cost effectiveness over their autologous counterparts, they nevertheless entail the culture of large batches of cells under cGMP conditions. It is clear that further optimization of these in vitro culture methodologies is required to improve therapeutic efficacy of DC-based vaccines. In order to home to draining $\mathrm{LN}$ and subsequently activate specific T cells, DC have to reach the correct level of activation and display the correct set of chemokine receptors, expression of which should be precisely orchestrated, both spatially and chronologically [33]. In vitro generated and readministered DC do not necessarily fulfill all these requirements, as only very low numbers of injected DC (typically $<1 \%$ ) reach the draining lymph nodes [7]. Therefore, next to improving whole tumor cell and/or DC-based vaccines, direct in vivo approaches certainly deserve more attention. Of note, many novel tools have now become available for targeting DC [49]. In parallel studies, therefore, we currently pursue the latter approach using DC-targeting adenoviral vectors carrying antigenic payloads $[5,6,54]$. At the end of the day, results from rigidly controlled and comparative clinical studies should reveal those immunotherapeutic approaches that deserve inclusion into regular cancer patient care.

Open Access This article is distributed under the terms of the Creative Commons Attribution Noncommercial License which permits any noncommercial use, distribution, and reproduction in any medium, provided the original author(s) and source are credited.

\section{References}

1. Baars A, Claessen AME, van den Eertwegh AJM, Gall HE, Stam AG, Meijer S, Giaccone G, Meijer CJ, Scheper RJ, Wagstaff J, 
Vermorken JB, Pinedo HM (2000) Skin tests predict survival after autologous tumor cell vaccination in metastatic melanoma: experience in 81 patients. Ann Oncol 11:965-970

2. Banchereau J, Palucka AK, Dhodapkar M, Burkeholder S, Taquet N, Rolland A, Taquet S, Coquery S, Wittkowski KM, Bhardwaj N, Pineiro L, Steinman R, Fay J (2001) Immune and clinical responses in patients with metastatic melanoma to CD34(+) progenitorderived dendritic cell vaccine. Cancer Res 61:6451-6458

3. Berd D, Sato T, Maguire HC Jr, Kairys J, Mastrangelo MJ (2004) Immunopharmacologcal analysis of an autologous, hapten-modified human melanoma vaccine. J Clin Oncol 22:403-415

4. Davis ID, Jefford M, Parente P, Cebon J (2003) Rational approaches to human cancer immunotherapy. J Leukoc Biol 73:3-29

5. de Gruijl TD, Luykx-de Bakker SA, Tillman BW, van den Eertwegh AJ, Buter J, Lougheed SM, van der Bij GJ, Safer AM, Haisma HJ, Curiel DT, Scheper RJ, Pinedo HM, Gerritsen WR (2002) Prolonged maturation and enhanced transduction of dendritic cells migrated from human skin explants after in situ delivery of CD40-targeted adenoviral vectors. J Immunol 169:53225331

6. de Gruijl TD, Ophorst OJ, Goudsmit J, Verhaagh S, Lougheed SM, Radosevic K, Havenga MJ, Scheper RJ (2006) Intradermal delivery of adenoviral type-35 vectors leads to high efficiency transduction of mature, CD8+ T-Cell-stimulating skin-emigrated dendritic cells. J Immunol 177:2208-2215

7. de Vries IJ, Krooshoop DJ, Scharenborg NM, Lesterhuis WJ, Diepstra JH, Van Muijen GN , Strijk SP, Ruers TJ, Boerman OC, Oyen WJ, Adema GJ, Punt CJ, Figdor CG (2003) Effective migration of antigen-pulsed dendritic cells to lymph nodes in melanoma patients is determined by their maturation state. Cancer Res 63:12-17

8. Disis ML, Bernhard H, Shiota FM, Hand SL, Gralow JR, Huseby ES, Gillis S, Cheever MA (1996) Granulocyte-macrophage colony-stimulating factor: an effective adjuvant for protein and peptide-based vaccines. Blood 88:202-210

9. Dranoff G, Jaffee E, Lazenby A, Golumbek P, Levitsky H, Brose K, Jackson V, Hamada H, Pardoll D, Mulligan RC (1993) Vaccination with irradiated tumor cells engineered to secrete murine granulocyte-macrophage colony-stimulating factor stimulates potent, specific, and long-lasting immunity. Proc Natl Acad Sci USA 90:3539-3543

10. Dranoff G (2002) GM-CSF-based cancer vaccines. Immunol Rev 188:147-154

11. Eager R, Nemunaitis J (2005) GM-CSF gene-transduced tumor vaccines. Mol Ther 12:18-27

12. Egen JG, Kuhns MS, Allison JP (2002) CTLA-4: new insights into its biological function and use in tumor immunotherapy. Nat Immunol 3:611-618

13. Fabre JW (2001) The allogeneic response and tumor immunity. Nat Med 7:649-652

14. Ferlazzo G, Wesa A, Wei WZ, Galy A (1999) Dendritic cells generated either from CD34+ progenitor cells or from monocytes differ in their ability to activate antigen-specific CD8+ T-cells. J Immunol 163:3597-3604

15. Fox JL (2007) Uncertainty surrounds cancer vaccine review at FDA. Nat Biotech 25:827-828

16. Gerritsen WR, van den Eertwegh AJM, de Gruijl TD, Giaccone G, Scheper RJ, Sacks N, Harding T, Lowy I, Stankevich E, Hege K (2007) Biochemical and immunologic correlates of clinical response in a combination trial of the GM-CSF-gene transduced allogeneic prostate cancer immunotherapy and ipilimumab in patients with metastatic hormone-refractory prostate cancer (mHRPC). ASCO Meeting Abstr 25:5120

17. Hanna MG Jr, Peters LC (1978) Immunotherapy of established micrometastases with a bacillus Calmette-Guerin tumour cell vaccine. Cancer Res 38:204-209
18. Hanna MG Jr, Brandhorst JS, Peters LC (1979) Active specific immunotherapy of residual micrometastases: an evaluation of sources, doses and ratios of BCG with tumour cells. Cancer Immunol Immunother 7:165-173

19. Hanna MG, Hoover HC, Vermorken JB, Harris JE, Pinedo HM (2001) Adjuvant active specific immunotherapy of stage II and stage III colon cancer with an autologous tumour cell vaccine: first randomized phase III trials show promise. Vaccine 19:2576-2582

20. Harris JE, Ryan L, Hoover HC Jr, Stuart RK, Oken MM, Benson AB 3rd, Mansour E, Haller DG, Manola J, Hanna MG Jr (2000) Adjuvant active specific immunotherapy for stage II and III colon cancer with an autologous tumour cell vaccine: eastern cooperative oncology group study E5283. J Clin Oncol 18:148-157

21. Hasebe H, Nagayama H, Sato K, Enomoto M, Takeda Y, Takahashi TA, Hasumi K, Eriguchi M (2000) Dysfunctional regulation of the development of monocyte-derived dendritic cells in cancer patients. Biomed Pharmacother 54:291-298

22. Hege KM, Jooss K, Pardoll D (2006) GM-CSF gene-modified cancer cell immunotherapies: of mice and men. Int Rev Immunol 25:321-352

23. Holtl L, Ramoner R, Zelle-Rieser C, Gander H, Putz T, Papesh C, Nussbaumer W, Falkensammer C, Bartsch G, Thurnher M (2005) Allogeneic dendritic cell vaccination against metastatic renal cell carcinoma with or without cyclophosphamide. Cancer Immunol Immunother 54:663-670

24. Hoover HC Jr, Brandhorst JS, Peters LC, Surdyke MG, Takeshita Y, Madariaga J, Muenz LR, Hanna MG Jr (1993) Adjuvant active specific immunotherapy for human colorectal cancer: 6.5- year median follow-up of a phase III prospectively randomized trial. J Clin Oncol 11:390-399

25. Hu ZB, Ma W, Zaborski M, MacLeod R, Quentmeier H, Drexler HG (1996) Establishment and characterization of two novel cytokine-responsive acute myeloid and monocytic leukemia cell lines, MUTZ-2 and MUTZ-3. Leukemia 10:1025-1040

26. Hurwitz AA, Foster BA, Kwon ED, Truong T, Choi EM, Greenberg NM, Burg MB, Allison JP (2000) Combination immunotherapy of primary prostate cancer in a transgenic mouse model using CTLA-4 blockade. Cancer Res 60:2444-2448

27. Hus I, Rolinski J, Tabarkiewicz J, Wojas K, Bojarska-Junak A, Greiner J, Giannopoulos K, Dmoszynska A, Schmitt M (2005) Allogeneic dendritic cells pulsed with tumor lysates or apoptotic bodies as immunotherapy for patients with early-stage B-cell chronic lymphocytic leukemia. Leukemia 19:1621-1627

28. Jaffee EM, Hruban RH, Biedrzycki B, Laheru D, Schepers K, Sauter PR, Goemann M, Coleman J, Grochow L, Donehower RC, Lillemoe KD, O'Reilly S, Abrams RA, Pardoll DM, Cameron JL, Yeo CJ (2001) Novel allogeneic granulocyte-macrophage colonystimulating factor-secreting tumour vaccine for pancreatic cancer: a phase I trial of safety and immune activation. J Clin Oncol 19:145-156

29. Jager E, Ringhoffer M, Dienes HP, Arand M, Karbach J, Jager D, Ilsemann C, Hagedorn M, Oesch F, Knuth A (1996) Granulocytemacrophage-colony-stimulating factor enhances immune responses to melanoma-associated peptides in vivo. Int J Cancer 67:54-62

30. Jocham D, Richter A, Hoffmann L, Iwig K, Fahlenkamp D, Zakrewski G, Schmitt E, Dannenberg T, Lehmacher W, von Wietersheim J, Doehn C (2004) Adjuvant autologous renal tumour cell vaccine and risk of tumour progression in patients with renal-cell carcinoma after radical nephrectomy: phase III, randomised controlled trial. The Lancet 363:594-599

31. Krieg AM (2003) CpG motifs: the active ingredient in bacterial extracts? Nat Med 9:831-835

32. Krieg AM (2006) Therapeutic potential of Toll-like receptor 9 activation. Nat Rev Drug Discov 5:471-484

33. Lesterhuis WJ, Aarntzen EH, De Vries IJ, Schuurhuis DH, Figdor CG, Adema GJ, Punt CJ (2008) Dendritic cell vaccines in 
melanoma: from promise to proof? Crit Rev Oncol Hematol [Epub ahead of print]

34. Masterson AJ, Sombroek CC, de Gruijl TD, Graus YM, van der Vliet HJ, Lougheed SM, van den Eertwegh AJ, Pinedo HM, Scheper RJ (2002) MUTZ-3, a human cell line model for the cytokineinduced differentiation of dendritic cells from CD34+ precursors. Blood 100:701-703

35. Michael A, Ball G, Quatan N, Wushishi F, Russell N, Whelan J, Chakraborty P, Leader D, Whelan M, Pandha H (2005) Delayed disease progression after allogeneic cell vaccination in hormoneresistant prostate cancer and correlation with immunologic variables. Clin Cancer Res 11:4469-4478

36. Neves AR, Ensina LF, Anselmo LB, Leite KR, Buzaid AC, Camara-Lopes LH, Barbuto JA (2005) Dendritic cells derived from metastatic cancer patients vaccinated with allogeneic dendritic cell-autologous tumor cell hybrids express more CD86 and induce higher levels of interferon-gamma in mixed lymphocyte reactions. Cancer Immunol Immunother 54:61-66

37. Petrylak DP, Macarthur RB, O'Connor J, Shelton G, Judge T, Balog J, Pfaff C, Bagiella E, Heitjan D, Fine R, Zuech N, Sawczuk I, Benson M, Olsson CA (1999) Phase I trial of docetaxel with estramustine in androgen-independent prostate cancer. J Clin Oncol 17:958-967

38. Ratzinger G, Baggers J, de Cos MA, Yuan J, Dao T, Reagan JL, Munz C, Heller G, Young JW (2004) Mature human Langerhans cells derived from CD34+ hematopoietic progenitors stimulate greater cytolytic $\mathrm{T}$ lymphocyte activity in the absence of bioactive IL-12p70, by either single peptide presentation or cross-priming than do dermal-interstitial or monocyte-derived dendritic cells. J Immunol 173:2780-2791

39. Santegoets SJAM, Schreurs MW, Masterson AJ, Liu YP, Goletz S, Baumeister H, Kueter EW, Lougheed SM, van den Eertwegh AJ, Scheper RJ, Hooijberg E, de Gruijl TD (2006a) In vitro priming of tumor-specific cytotoxic $\mathrm{T}$ lymphocytes using allogeneic dendritic cells derived from the human MUTZ-3 cell line. Cancer Immunol Immunother 55:1480-1490

40. Santegoets SJAM, Masterson AJ, van der Sluis PC, Lougheed SM, Fluitsma DM, van den Eertwegh AJ, Pinedo HM, Scheper RJ, de Gruijl TD (2006b) A CD34(+) human cell line model of myeloid dendritic cell differentiation: evidence for a CD14(+) CD11b(+) Langerhans cell precursor. J Leukoc Biol 80:1337-1344

41. Santegoets SJAM, Bontkes HJ, Stam AGM, Bhoelan F, Ruizendaal JJ, van den Eertwegh AJM, Hooijberg E, Scheper RJ, de Gruijl TD (2008) Inducing anti-tumor T-cell immunity: comparative functional analysis of interstitial versus Langerhans dendritic cells in a human cell line model. J Immunol 180:4540-4549

42. Savarese DM, Halabi S, Hars V, Akerley WL, Taplin ME, Godley PA, Hussain A, Small EJ, Vogelzang NJ (2001) Phase II study of docetaxel, estramustine, low-dose hydrocortisone in men with hormone-refractory prostate cancer: a final report of CALGB 9780. Cancer and Leukemia Group B. J Clin Oncol 19:2509-2516

43. Siders WM, Vergilis KL, Johnson C, Shields J, Kaplan JM (2003) Induction of specific antitumor immunity in the mouse with the electrofusion product of tumor cells and dendritic cells. Mol Ther 7:498-505

44. Simons JW, Carducci MA, Mikhak B, Lim M, Biedrzycki B, Borellini F, Clift SM, Hege KM, Ando DG, Piantadosi S (2006) Phase I/II trial of an allogeneic cellular immunotherapy in hormone-naïve prostate cancer. Clin Cancer Res 12:3394-3401

45. Small EJ, Schellhammer PF, Higano CS, Redfern CH, Nemunaitis JJ, Valone FH, Verjee SS, Jones LA, Hershberg RM (2006) Placebo-controlled phase III trial of immunologic therapy with sipuleucel-T (APC8015) in patients with metastatic, asymptomatic hormone refractory prostate cancer. J Clin Oncol 24:3089-3094

46. Small EJ, Sacks N, Nemunaitis J, Urba WJ, Dula E, Centeno AS, Nelson WG, Ando D, Howard C, Borellini F, Nguyen M,
Hege K, Simons JW (2007) Granulocyte macrophage colonystimulating factor-secreting allogeneic cellular immunotherapy for hormone-refractory prostate cancer. Clin Cancer Res 13:38833891

47. Small EJ, Tchekmedyian NS, Rini BI, Fong L, Lowy I, Allison JP (2007) A pilot trial of CTLA-4 blockade with human anti-CTLA4 in patients with hormone-refractory prostate cancer. Clin Cancer Res 13:1810-1815

48. Suzuki T, Fukuhara T, Tanaka M, Nakamura A, Akiyama K, Sakakibara T, Koinuma D, Kikuchi T, Tazawa R, Maemondo M, Hagiwara K, Saijo Y, Nukiwa T (2005) Vaccination of dendritic cells loaded with interleukin-12-secreting cancer cells augments in vivo antitumor immunity: characteristics of syngeneic and allogeneic antigen-presenting cell cancer hybrid cells. Clin Cancer Res 11:58-66

49. Tacken PJ, de Vries IJ, Torensma R, Figdor CG (2007) Dendriticcell immunotherapy: from ex vivo loading to in vivo targeting. Nat Rev Immunol 7:790-802

50. Tamir A, Basagila E, Kagahzian A, Jiao L, Jensen S, Nicholls J, Tate P, Stamp G, Farzaneh F, Harrison P, Stauss H, George AJ, Habib N, Lechler RI, Lombardi G (2007) Induction of tumor-specific $\mathrm{T}$-cell responses by vaccination with tumor lysate-loaded dendritic cells in colorectal cancer patients with carcinoembryonic-antigen positive tumors. Cancer Immunol Immunother 56:2003-2016

51. Tanaka Y, Koido S, Chen D, Gendler SJ, Kufe D, Gong J (2001) Vaccination with allogeneic dendritic cells fused to carcinoma cells induces antitumor immunity in MUC1 transgenic mice. Clin Immunol 101:192-200

52. Tarr PE (1996) Granulocyte-macrophage colony-stimulating factor and the immune system. Med Oncol 13:133-140

53. Thompson RH, Allison JP, Kwon ED (2006) Anti-cytotoxic t lymphocyte (CTLA-4) immunotherapy for the treatment of prostate cancer. Urol Oncol 24:442-447

54. Tillman BW, Hayes TL, de Gruijl TD, Douglas JT, Curiel DT (2000) Adenoviral vectors targeted to CD40 enhance the efficacy of dendritic cell-based vaccination against human papillomavirus 16-induced tumor cells in a murine model. Cancer Res 60:54565463

55. Trefzer U, Weingart G, Chen Y, Herberth G, Adrian K, Winter H, Audring H, Guo Y, Sterry W, Walden P (2000) Hybrid cell vaccination for cancer immune therapy: first clinical trial with metastatic melanoma. Int J Cancer 85:618-626

56. Trefzer U, Herberth G, Wohlan K, Milling A, Thiemann M, Sherev T, Sparbier K, Sterry W, Walden P (2004) Vaccination with hybrids of tumor and dendritic cells induces tumor-specific T-cell and clinical responses in melanoma stage III and IV patients. Int J Cancer 110:730-740

57. Trefzer U, Herberth G, Wohlan K, Milling A, Thiemann M, Sharav T, Sparbier K, Sterry W, Walden P (2005) Tumour-dendritic hybrid cell vaccination for the treatment of patients with malignant melanoma: immunological effects and clinical results. Vaccine 23:2367-2373

58. Yasuda T, Kamigaki T, Kawasaki K, Nakamura T, Yamamoto M, Kanemitsu K, Takase S, Kuroda D, Kim Y, Ajiki T, Kuroda Y (2007) Superior anti-tumor protection and therapeutic efficacy of vaccination with allogeneic and semiallogeneic dendritic cell/tumor cell fusion hybrids for murine colon adenocarcinoma. Cancer Immunol Immunother 56:1025-1036

59. van den Eertwegh AJM, Lensen RJ, Scheper RJ, Giaccone G, Meijer CJLM, Bontkes HJ, Gruijl TD, Hooijberg E (2006) Autologous tumor cell vaccination with PF-3512676 (CPG 7909) and GM-CSF followed by subcutaneous PF-3512676 and IFN-alpha for patients with metastatic renal cell carcinoma. ASCO Meeting Abstr 24:2530

60. van Elsas A, Hurwitz AA, Allison JP (1999) Combination immunotherapy of B16 melanoma using anti-cytotoxic T lymphocyte- 
associated antigen 4 (CTLA-4) and granulocyte/macrophage colony-stimulating factor (GM-CSF)-producing vaccines induces rejection of subcutaneous and metastatic tumors accompanied by autoimmune depigmentation. J Exp Med 190:355-366

61. van Elsas A, Sutmuller RP, Hurwitz AA, Ziskin J, Villasenor J, Medema JP, Overwijk WW, Restifo NP, Melief CJM, Offringa R, Allison JP (2001) Elucidating the autoimmune and antitumor effector mechanisms of a treatment based on cytotoxic $\mathrm{T}$ lymphocyte antigen- 4 blockade in combination with a B16 melanoma vaccine: comparison of prophylaxis and therapy. J Exp Med 194:481-489

62. Vermorken JB, Claessen AM, van Tinteren H, Gall HE, Ezinga R, Meijer S, Scheper RJ, Meijer CJLM, Bloemena E, Ransom JH, Hanna MG Jr, Pinedo HM (1999) Active specific immunotherapy for stage II and stage III human colon cancer: a randomised trial. Lancet 353:345-350

63. Anonymous (2008) The regulator disapproves. Nat Biotechnol 26:1 